\title{
Predictors of Fluvoxamine Response in Contamination-related Obsessive Compulsive Disorder: A PET Symptom Provocation Study
}

Scott L. Rauch, M.D., Lisa M. Shin, Ph.D., Darin D. Dougherty, M.D., Nathaniel M. Alpert, Ph.D., Alan J. Fischman, M.D., Ph.D., and Michael A. Jenike, M.D.

The purpose of this study was to identify neuroimaging predictors of medication response in contamination-related obsessive compulsive disorder (OCD). Prior studies of OCD had indicated that glucose metabolic rates within orbitofrontal cortex (OFC) were inversely correlated with subsequent response to serotonergic reuptake inhibitors (SRIs) and that glucose metabolic rates within posterior cingulate cortex (PCC) were positively correlated with subsequent response to cingulotomy. Nine subjects with contamination-related OCD underwent a 12-week open trial of treatment with the SRI fluvoxamine. Percent change in Yale-Brown Obsessive Compulsive Scale score, from preto post-treatment, served as the index of treatment response. Positron emission tomography (PET) measurements of regional cerebral blood flow ( $\mathrm{CCBF}$ ) were obtained prior to treatment, in the context of a symptom provocation paradigm. Statistical parametric mapping was used to identify brain loci where pre-treatment $r C B F$ was significantly correlated with subsequent treatment response. Consistent with a priori hypotheses, lower $r C B F$ values in OFC and higher $r C B F$ values in PCC predicted better treatment response. This same pattern of associations was present regardless of whether the imaging data were acquired during a provoked or neutral state. These findings are consistent with prior studies of $O C D$, indicating that PET indices of brain activity within OFC are inversely correlated with subsequent response to SRIs. In addition, similar to findings regarding cingulotomy for $O C D$, indices of activity within PCC appear to be positively correlated with response to fluvoxamine as well. Finally, this pattern is sufficiently robust as to be relatively independent of symptomatic state at the time of tracer uptake.

[Neuropsychopharmacology 27:782-791, 2002] (C) 2002 American College of Neuropsychopharmacology. Published by Elsevier Science Inc.
From the Departments of Psychiatry (SLR, LMS, DDD, MAJ) and Radiology (SLR, DDD, NMA, AJF), Massachusetts General Hospital and Harvard Medical School, Boston, MA; and Department of Psychology (LMS), Tufts University, Medford, MA.

Address correspondence to: Scott L. Rauch, M.D., Department of Psychiatry, Massachusetts General Hospital - East, 9th Floor, Bldg. 149, 13th Street, Charlestown, MA 02129. Tel.: (617) 724-9553; Fax: (617) 726-4078; E-mail: rauch@psych.mgh.harvard.edu

Received November 14, 2001; revised April 10, 2002; accepted April 15, 2002

Online publication: 4/18/02 at www.acnp.org/citations/ Npp041902287.
KEY WORDS: Anxiety; Orbitofrontal cortex; Positron emission tomography; Posterior cingulate cortex; Serotonergic reuptake inhibitor; Neuroimaging

Functional imaging research has contributed substantially to contemporary neurocircuitry models of obsessive compulsive disorder (OCD) (Rauch 2000; Rauch and Baxter 1998; Saxena et al. 1998). Convergent findings have implicated a network of brain regions, including orbitofrontal cortex (OFC), anterior cingulate cortex, and the striatum, in the pathophysiology of 
OCD. These areas exhibit hyperactivity at rest that is accentuated during symptom provocation and attenuated following successful treatment.

One promising clinical application of neuroimaging is to identify predictors of treatment response. Three prospective studies of OCD patients have already found that pre-treatment positron emission tomography (PET) measurements of cerebral metabolic rates within OFC significantly predict subsequent response to treatment with serotonergic reuptake inhibitors (SRIs) (Brody et al. 1998; Saxena et al. 1999; Swedo et al. 1992). Specifically, lower pre-treatment rates of metabolism within OFC have consistently been associated with better subsequent responses to SRIs. Conversely, in one of these reports (Brody et al. 1998), higher cerebral metabolic rates within left OFC were associated with better responses to behavioral therapy.

Recently, an initial study was conducted examining PET cerebral metabolic correlates as potential predictors of response to anterior cingulotomy in patients with OCD (Rauch et al. 2001b). Rauch and colleagues found that higher cerebral metabolic rates within posterior cingulate cortex (PCC) were associated with better subsequent response to cingulotomy. However, the cingulotomy study differed from previous studies of SRIs in that statistical parametric mapping rather than region of interest (ROI)-based methods of data analysis were used. Therefore, it remained unclear whether the unique findings regarding the PCC were indicative of: (1) the difference in treatment type (i.e., cingulotomy vs. SRIs); (2) the difference in data analytic methods (i.e., statistical parametric mapping vs. ROI-based); or (3) differences in the patient groups studied (i.e., severe treatment-refractory patients on medications vs. a conventional sample of patients with OCD, off medications).

In the current study, we sought to build on the previous body of research in this area. Specifically, we sought to study PET predictors of SRI treatment response using statistical parametric mapping methods. Moreover, we employed a symptom provocation design, so that we could compare the profiles of PET predictors of treatment response during a provoked symptomatic state versus a neutral state. Thus, we tested the a priori hypotheses that lower $\mathrm{rCBF}$ within $\mathrm{OFC}$ and higher $\mathrm{rCBF}$ within PCC would be associated with better subsequent response to SRIs. Moreover, we were able to investigate whether there are qualitative or quantitative differences between the PET predictive profiles obtained using a symptom provocation versus a neutral state design.

Finally, it occurred to us that past studies regarding neuroimaging predictors of treatment response might have been confounded by differences in OCD symptom types among the subjects. There is evidence that different OCD symptom dimensions (see Baer 1994; Leckman et al. 1997) might be associated with different rates of response to various treatments (Mataix-Cols et al. 1999) and also different neuroimaging profiles (Rauch et al. 1998a). Thus, for instance, if washing and contamination symptoms are associated with both PET measures of OFC activity and subsequent SRI treatment response, then the apparent predictive value of PET measures within OFC may be confounded by this mediating variable. Consequently, in the current experiment, we limited enrollment to subjects with OCD principally related to contamination symptoms. By studying a relatively homogeneous patient population, we mitigate the potentially confounding influences of OCD symptom dimensions. Of course, this strategy has the limitation of potentially limiting the generalizability of the current findings to the broader population of people with OCD.

\section{MATERIALS AND METHODS}

\section{Subjects}

This study was conducted with the approval of the Subcommittee on Human Studies of The Massachusetts General Hospital (MGH); written informed consent was obtained from each subject. The subjects were nine right-handed (Oldfield 1971) patients (four male, five female) meeting DSM-IIIR criteria for OCD (American Psychiatric Association 1987) with mean ( \pm SD) age of 28.8 ( \pm 8.2 ; range 18 to 41 ) years. Entry criteria required not only that patients have an OCD diagnosis by SCID (Spitzer et al. 1998) and be right-handed, but also that they reported contamination symptoms as their primary manifestations of OCD. Further, exclusion criteria required that subjects be free of current major depression or substance abuse; have no lifetime history of bipolar disorder, primary psychotic disorder, substance dependence disorder; no history of seizure disorder or head trauma with loss of consciousness; and no history of any other major medical disorder. All subjects were off psychotropic medications for at least four weeks prior to the initial PET session (at least six weeks for fluoxetine). Subjects were ineligible for participation if they had a history of prior treatment with fluvoxamine.

\section{PET Symptom Provocation Paradigm}

The symptom provocation paradigm that we used has been described previously (Rauch et al. 1994). Briefly, after an initial habituation phase, PET rCBF data were acquired twice during a Neutral condition, while subjects responded to an innocuous control stimulus, and twice again during a Provoked condition, while they responded to a provocative stimulus that was tailored to induce each patient's symptoms. In all cases, the subjects participated in the process of identifying an appropri- 
ately provocative stimulus, so as to insure sufficient but not overwhelming provocation of their OCD contamination symptoms. A balanced order paradigm intended to control for order effects was deemed impractical; our past experience has shown that once provoked, OCD subjects often remain symptomatic for up to several hours, precluding a paradigm dependent upon prompt return to a relatively asymptomatic state (e.g., see Rauch et al. 1994).

Ten point analog scales based on self-reporting were utilized to quantify the severity of each subject's anxiety (Anxiety analog scale (AAS)) and OCD symptoms (OCD analog scale (OCDAS)) during the initial habituation period as well as during each scanning period. A response of ten was equated with the most severe symptoms ever previously experienced by the subject; zero was equated with complete absence of symptoms. These scales provided clinical measures by which to gauge the magnitude of each subject's response during the different conditions (Neutral and Provoked).

After being fully situated in the scanner, each subject was allowed to habituate, during which time analog scale scores were obtained every three minutes. Completion of habituation was operationalized as both AAS and OCDAS scores remaining constant for two consecutive measurement periods.

Following habituation, each subject proceeded to the Neutral phase of the paradigm. For each of two Neutral scans, the subject was exposed to an innocuous stimulus matched to his individualized provocative stimulus in terms of primary sensory stimulation. For example, the subject was shown a "clean" glove, and it was identified to him as such. The "clean" glove was then placed on his hand, and remained there for approximately 2 $\mathrm{min}$, throughout the acquisition phase for the first Neutral scan. Immediately after placement of the stimulus, the subject was instructed to close his eyes and to allow his thoughts to focus on the stimulus. Once his eyes were closed, PET acquisition commenced. At the end of each scan, the glove was removed and the subject was asked to indicate the severity of his anxiety and OCD symptoms on the corresponding scales. This procedure was repeated to achieve a complete set of data for each of two Neutral scans for each subject.

Next, the procedure was repeated for two Provoked scans, during which the subject was exposed to an individualized provocative stimulus (e.g., a "contaminated" glove) in place of the innocuous stimulus. In all conditions, the scans were performed with low background noise and lighting, with eyes closed and ears unplugged. Also, note that the laterality of exposure (left hand; right hand) was counterbalanced across scans and subjects.

\section{Positron Emission Tomography}

The patient's head was immobilized with a custom fabricated head-holder (Tru Scan Image Inc., Annapolis,
MD), positioned within the PET camera so that the imaging plane was parallel to the orbito-meatal line. Emission data were acquired with a Scanditronix PC4096 PET camera (General Electric, Milwaukee, Wisconsin), in a single bed position for $30 \mathrm{~min}$. The primary imaging parameters of the PC4096 camera are in-plane and axial resolutions of $6.0 \mathrm{~mm}$ full width at half maximum (FWHM), 15 contiguous slices of $6.5 \mathrm{~mm}$ separation and sensitivity of $\sim 135 \mathrm{cps} / \mathrm{Kbq}$. All images were reconstructed using a conventional filtered back-projection algorithm to an in-plane resolution of $7 \mathrm{~mm}$ FWHM. Projection data were corrected for nonuniformity of detector response, dead time, random coincidences and scattered radiation. An analytic attenuation correction was applied to the data based on an estimate of slice contour and the assumption of uniform attenuation coefficient equal to that of water, rather than obtaining and using individually measured attenuation values.

Following reconstruction, movement corrected (Alpert et al. 1996), whole brain normalized images reflecting relative regional cerebral blood flow ( $\mathrm{rCBF}$ ) were transformed to the standardized normalized space established by the Montreal Neurological Institute (MNI; http://www.bic.mni.mcgill.ca/). Following spatial normalization, scans were filtered with a $20 \mathrm{~mm}$ FWHM two-dimensional Gaussian filter.

\section{Treatment Trial}

Following informed consent, entry into the study, clinical evaluation, and pre-treatment PET scanning, patients proceeded with an open fluvoxamine trial. In addition to the initial clinical assessment (prior to scanning), subjects were seen and evaluated monthly. Patients were advanced on medication toward a target dose of $300 \mathrm{mg}$ per day of fluvoxamine during the first month of treatment. The target or maximum tolerated dose was achieved by the one month follow-up visit, and maintained for the additional two months. The primary outcome measure of treatment response was \% decrease in Yale-Brown Obsessive Compulsive Scale (Y-BOCS; Goodman et al. 1989) score from pre-treatment to the three month post-treatment time point. The Beck Depression Inventory (BDI; Beck 1961) was also administered at pre-treatment and post-treatment time points, as a measure of depressive symptom severity. This test provided a means for assessing change in depressive symptoms as a potentially confounding factor.

\section{Statistical Analyses}

Positron emission tomography data analysis followed the theory of statistical parametric mapping (Friston et al. 1991, 1994, 1995; Worsley et al. 1992), and was performed with SPM99 software (Wellcome Dept. of Cognitive Neurology, London, UK). Across the entire cohort 
of subjects, several sets of statistical parametric maps were generated: First, the effects of symptom provocation were assessed by performing a direct contrast between the Provoked and the Neutral state conditions. Next, the principal correlation maps were generated, reflecting the relationship between $\mathrm{rCBF}$ and \% improvement in Y-BOCS; such maps were made separately for the Neutral state and Provoked state conditions. For each correlation map, the covariates only option was selected, so that a regression analysis was performed to test the linear relationship between $\mathrm{rCBF}$ and subsequent treatment response (across subjects), yielding a Z-score at each voxel in space. For ease of discussion, we refer to the findings in terms of significant "correlations", although the analysis employed formally involved linear regression, rather than assessment of correlation per se. Both direct and inverse relationships were assessed.

The statistical parametric maps were inspected to identify all foci of significant activation (in the case of the Provoked vs. Neutral contrast) or significant correlations (in the case of the correlation maps). Given the strong nature of a priori hypotheses, in the context of similar past findings, $\mathrm{Z}>3.09$ ( $p<.001$, uncorrected for multiple comparisons) was selected as the threshold for statistical significance. Based on previous OCD symptom provocation studies (Breiter et al. 1996; McGuire et al. 1994; Rauch et al. 1994), we predicted activation in OFC, anterior cingulate cortex, and the caudate nucleus. Based on previous imaging studies of predictors of treatment response in OCD (Brody et al. 1998; Rauch et al. 2001b; Saxena et al. 1999; Swedo et al. 1992), we predicted correlations in OFC and PCC. Loci exhibiting effects of comparable statistical significance are also reported for completeness, and to obviate bias. However, such findings should not be taken as significant in the absence of a priori hypotheses, until replicated.

\section{RESULTS}

\section{Treatment Response}

All nine subjects achieved the target dose of $300 \mathrm{mg} /$ day, and completed the 12-week open trial of fluvoxamine. Clinical outcome data are presented in Table 1. Note that the mean Y-BOCS improvement for this cohort was $39.9 \pm 31.4 \%$, with six of nine subjects $(67 \%)$ exhibiting greater than $25 \%$ reduction in OCD symptom severity. In addition to significant decreases in Y-BOCS scores $(\mathrm{t}(8)=3.58 ; p=.007)$, subjects also enjoyed a significant decrease in depression, as indicated by a $53.6 \pm 69.2 \%$ reduction in BDI scores $(\mathrm{t}(8)=2.56$; $p=.034)$.

\section{Subjective Ratings of Symptom Severity}

As a simple manipulation check, overall, AAS and OCDAS scores indicated successful provocation of OCD symptoms during the Provoked vs. the Neutral condition. Specifically, OCDAS scores were $5.2 \pm 2.3$ for the Provoked condition vs. $2.2 \pm 1.9$ for the Neutral condition $(\mathrm{t}(8)=4.00, p=.004)$; AAS scores were $4.3 \pm 2.1$ for the Provoked condition vs. $2.3 \pm 1.9$ for the Neutral condition $(\mathrm{t}(8)=4.63, p=.002)$.

\section{Neuroimaging Results of Symptom Provocation}

Consistent with a priori hypotheses, the Provoked versus Neutral contrast yielded significant activation within right anterior and lateral OFC (see Table 2). No significant activation was found within the other predicted regions (i.e., anterior cingulate cortex and caudate nucleus). Other loci of comparable activation were found within other frontal cortical areas and precuneus.

Table 1. Demographic and Clinical Data by Subject

\begin{tabular}{|c|c|c|c|c|c|c|c|c|c|}
\hline \multirow[b]{2}{*}{ Subjects } & \multirow[b]{2}{*}{ Sex } & \multirow[b]{2}{*}{ Age (yrs) } & \multirow[b]{2}{*}{ Comorbid Dx } & \multicolumn{2}{|c|}{ Pre-treatment } & \multicolumn{2}{|c|}{ Post-treatment } & \multicolumn{2}{|c|}{$\%$ Improvement } \\
\hline & & & & Y-BOCS & BDI & Y-BOCS & BDI & Y-BOCS & BDI \\
\hline 1 & $\mathrm{M}$ & 41 & none & 29 & 12 & 27 & 6 & 6.9 & 50.0 \\
\hline 2 & $\mathrm{M}$ & 34 & none & 23 & 22 & 11 & 3 & 52.2 & 86.4 \\
\hline 3 & M & 28 & none & 25 & 16 & 17 & 2 & 32.0 & 87.5 \\
\hline 4 & M & 36 & none & 15 & 2 & 16 & 4 & -6.7 & -100.0 \\
\hline 5 & $\mathrm{~F}$ & 19 & none & 23 & 5 & 12 & 6 & 47.8 & -20.0 \\
\hline 6 & $\mathrm{~F}$ & 18 & none & 23 & 5 & 14 & 0 & 39.1 & 100.0 \\
\hline 7 & $\mathrm{~F}$ & 21 & dysthymia & 30 & 47 & 3 & 1 & 90.0 & 97.9 \\
\hline 8 & $\mathrm{~F}$ & 27 & panic + agor. & 25 & 21 & 20 & 4 & 20.0 & 81.0 \\
\hline 9 & $\mathrm{~F}$ & 35 & GAD & 18 & 8 & 4 & 0 & 77.8 & 100.0 \\
\hline Mean & & 28.8 & & 23.4 & 15.3 & 13.8 & 2.9 & 39.9 & 53.6 \\
\hline [SD] & & [8.2] & & [4.7] & [13.9] & [7.5] & [2.3] & [31.4] & [69.2] \\
\hline
\end{tabular}

Dx, diagnosis; Y-BOCS, Yale-Brown Obsessive Compulsive Scale; BDI, Beck Depression Inventory; M, male; F, female;

Panic + agor., panic disorder with agoraphobia; GAD, generalized anxiety disorder 
Table 2. Neuroimaging Results: Loci of Significant Activation with Symptom Provocation

\begin{tabular}{|c|c|}
\hline Brain Regions & $\begin{array}{c}\text { Z-score ( } x, y, z \text { cordinates }) \\
\text { Provoked vs. Neutral Contrast }\end{array}$ \\
\hline \multicolumn{2}{|l|}{ A priori } \\
\hline Right Orbitofrontal Cortex (Area 47) & $4.30(50,24,-10)$ \\
\hline Right Orbitofrontal Cortex (Area 11) & $3.40(22,58,-20)$ \\
\hline Right Orbitofrontal Cortex (Area 11) & $3.27(34,52,-12)$ \\
\hline \multicolumn{2}{|l|}{ Post hoc } \\
\hline Right Frontal Cortex (Area 10) & $4.36(36,50,14)$ \\
\hline Right Frontal Cortex (Area 46) & $4.03(44,28,32)$ \\
\hline Left Premotor Cortex (Area 6) & $3.97(-42,-2,32)$ \\
\hline Right Frontal Cortex (Area 8) & $3.65(30,8,56)$ \\
\hline Right Frontal Cortex (Area 8) & $3.65(6,30,48)$ \\
\hline Left Precuneus (Area 7) & $3.55(-16,-74,52)$ \\
\hline Left Frontal Cortex (Area 9/46) & $3.50(-42,38,30)$ \\
\hline Left Frontal Cortex (Area 10/46) & $3.47(-38,50,8)$ \\
\hline
\end{tabular}

\section{Neuroimaging Predictors of Treatment Response}

First, the relationship between $\mathrm{rCBF}$ and \% Y-BOCS improvement was assessed for the Neutral condition. All analyses were then repeated for the Provoked condition. For both Neutral and Provoked conditions, loci of significant negative correlation were found within bilateral OFC and loci of significant positive correlation were found within bilateral PCC (see Table 3, Figure 1, and Figure 2).

Next, a series of ANCOVA analyses were performed to assess whether the loci of significant correlation found in the analysis of \%Y-BOCS improvement might be confounded by other clinical factors. Four separate ANCOVA maps were generated, each constructed to assess the relationship between $\mathrm{rCBF}$ and \%Y-BOCS improvement, while considering one of four potentially confounding clinical factors as a nuisance covariate. In each case, the significant correlation at the locus identified in the initial analysis survived, indicating that the central findings of this study are not confounded by a relationship between $\mathrm{rCBF}$ in the identified regions and age, pre-treatment severity of OCD symptoms, pre-

Table 3. Neuroimaging Results: Loci of Significant Correlations between Pre-treatment rCBF and Subsequent Response to Fluvoxamine

\begin{tabular}{|c|c|c|}
\hline \multirow[b]{2}{*}{ Brain Regions } & \multicolumn{2}{|c|}{ Z-score ( $x, y, z$ cordinates $)$} \\
\hline & Neutral Condition & Provoked Condition \\
\hline \multicolumn{3}{|l|}{ Negative Correlations } \\
\hline \multicolumn{3}{|l|}{ A priori } \\
\hline Right Orbitofrontal Cortex (Area 11) & $4.55(32,32,-22)$ & $4.86(34,30,-20)$ \\
\hline \multirow[t]{2}{*}{ Left Orbitofrontal Cortex (Area 11) } & $4.98(-20,34,22)$ & $4.35(-18,44,-26)$ \\
\hline & $4.12(-6,42,-26)$ & $3.94(-32,28,-10)$ \\
\hline \multicolumn{3}{|l|}{ Post hoc } \\
\hline Left Superior Temporal Gyrus (Area 22) & - & $3.28(-60,-46,20)$ \\
\hline Right Frontal Corteax (Area 8) & $3.43(18,50,40)$ & - \\
\hline \multicolumn{3}{|l|}{ Positive Correlations } \\
\hline \multicolumn{3}{|l|}{ A priori } \\
\hline Right Posterior Cingulate Cortex (Area 31) & $3.49(18,-32,44)$ & $3.39(20,-26,46)$ \\
\hline Left Posterior Cingulate Cortex (Area 31) & $4.38(-20,-30,38)$ & $3.31(-12,-20,38)$ \\
\hline \multicolumn{3}{|l|}{ Post hoc } \\
\hline Left Frontal Cortex (Area 8) & $3.47(-8,38,58)$ & $3.36(-12,38,56)$ \\
\hline Right Frontal Cortex (Area 8) & - & $3.21(12,40,52)$ \\
\hline
\end{tabular}

Z-scores correspond to the actual maximum pixel value within the brain region from the SPM. Coordinates defining the location of the maximum pixel values in MNI space are expressed as " $x, y, z$ "; in millimeters, $x>0$ is right of the midsagittal plane, $y>0$ is anterior to the anterior commissure, and $\mathrm{z}>0$ is superior to the intercommissural plane. Approximate Brodmann areas are given in parentheses. 


\section{NEGATIVE CORRELATION}
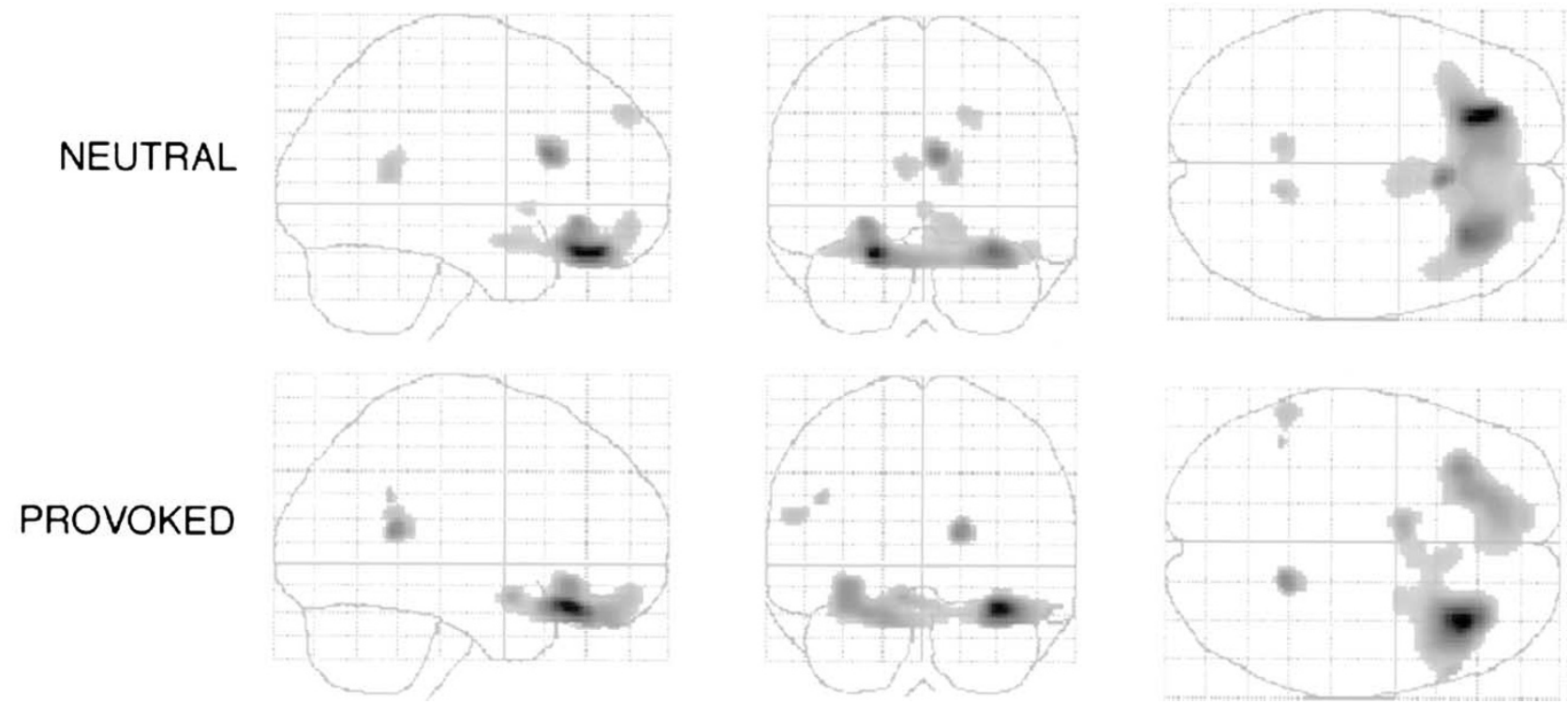

Figure 1. For both Neutral and Provoked conditions, the spatial extent of significant negative correlations between rCBF in OFC and subsequent fluvoxamine response is illustrated, via SPM "glass-through projections" from the conventional orthogonal perspectives. The maps are thresholded to display in gray scale those voxels corresponding to Z-scores $\geqslant 3.09$.

treatment severity of depressive symptoms, or improvement in severity of depressive symptoms.

\section{DISCUSSION}

Our current findings indicate that pre-treatment $\mathrm{rCBF}$ within OFC and PCC predict subsequent reduction in OCD symptom severity associated with fluvoxamine treatment. These statistical results do not appear to be attributable to confounding factors such as age, severity of OCD, or depression at the time of PET data acquisition, nor reduction in severity of depression during treatment. In addition, these findings do not appear to be confounded by different OCD symptom dimensions, to the extent that we limited the study cohort to patients with OCD symptoms principally related to contamination. Also, these same results were garnered regardless of whether imaging data were obtained during a symptomatic (Provoked) or control (Neutral) state.

The inverse correlation between rCBF in OFC and subsequent symptomatic improvement with SRI treatment is consistent with results from three previous studies of OCD employing other SRIs, PET-FDG, and ROI-based analytic methods (Brody et al. 1998; Saxena et al. 1999; Swedo et al. 1992). Taken together, these studies underscore the reliability of this finding in OCD, across SRIs, imaging modalities, and data ana- lytic methods. It has been proposed that SRIs might have their beneficial antiobsessional effects by enhancing serotonergic transmission within $\mathrm{OFC}$, that in turn modulates GABAergic tone within this region (see Blier and Bouchard 1994; Mansari et al. 1995; Rauch et al. 1998b). Certainly, the OFC has been the most consistently implicated region in neuroimaging studies of OCD; both in terms of between-group differences at rest and within-group differences over time, where attenuation of OFC hyperactivity has been associated with successful treatment (e.g., Baxter et al. 1992; see Rauch and Baxter 1998 for review). The current study found OFC activation during the provoked versus neutral state. Taken together, imaging findings in OCD suggest that OFC hyperactivity is associated with the symptomatic state (Rauch et al. 1994; Breiter et al. 1996), and that the magnitude of OFC hyperactivity may be related to both the severity of symptoms and also the degree of treatment-refractoriness. However, such a model is an oversimplification. For instance, in some cases OFC activity in OCD seems to be inversely related to symptom severity (Rauch et al. 1994), and positively correlated with treatment response (Brody et al. 1998). Hence more complex models are necessary to capture this complexity.

The positive correlation between rCBF in PCC and subsequent symptomatic improvement with SRI treatment, demonstrated here, parallels the results of an 


\section{POSTERIOR CINGULATE CORTEX}

LEFT

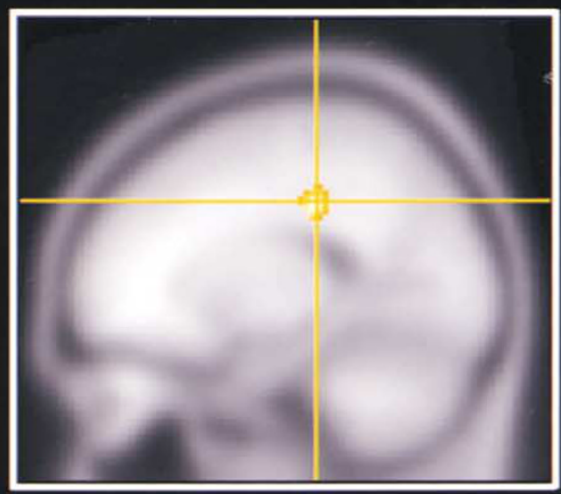

RIGHT

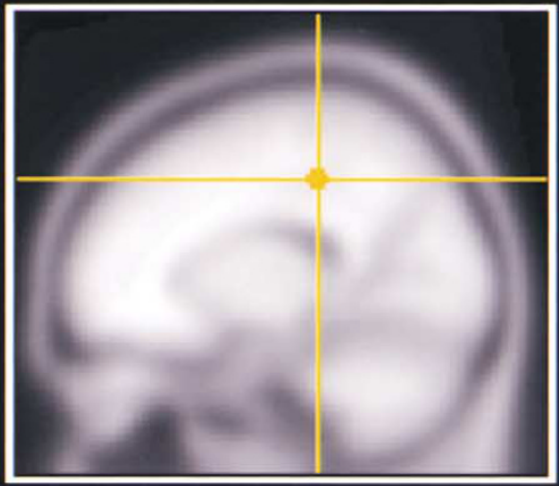

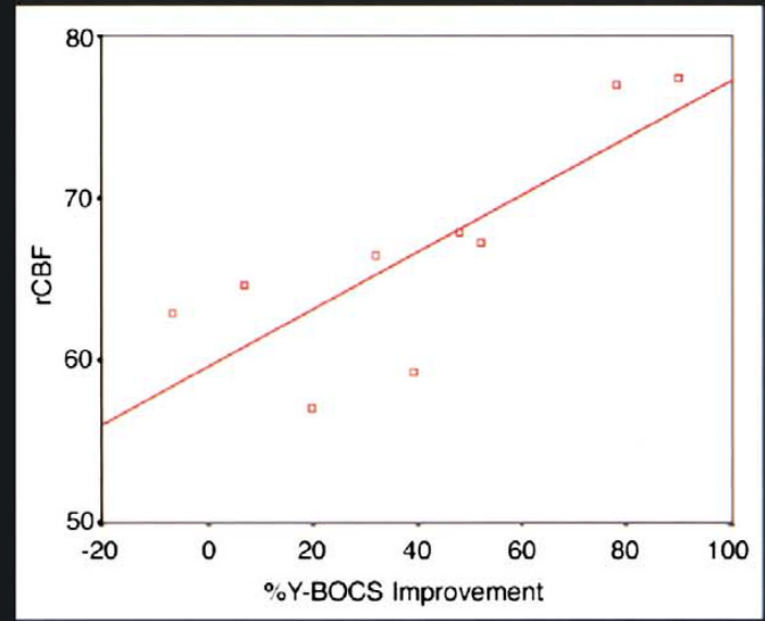

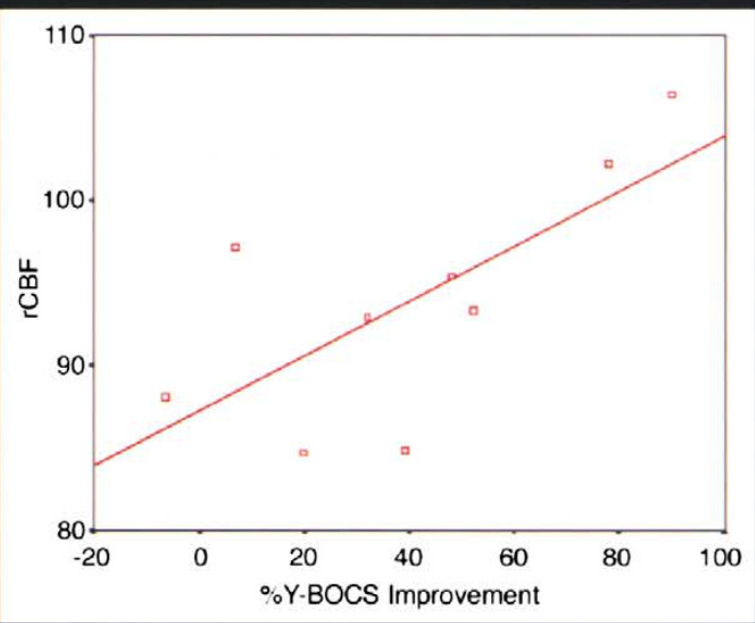

Figure 2. Exemplary data are presented for the Neutral condition. In the upper panels, the locations of significant positive correlations between rCBF in PCC and subsequent fluvoxamine response are illustrated, superimposed over the SPM99 template in MNI space for anatomic reference. Voxels corresponding to significant correlations (Z-score $\geqslant 3.09)$ are coded in yellow and the crosshair marks the location of the voxel with the maximum Z-score. The lower panels show the actual corresponding plots of \%Y-BOCS improvement vs. rCBF, taken from the voxel with the maximum Z-score, for right and left PCC respectively.

earlier study showing a positive correlation between cerebral metabolic rates in PCC and subsequent symptomatic improvement associated with anterior cingulotomy for OCD (Rauch et al. 2001b). This suggests that functional neuroimaging measures of PCC activity in OCD may predict subsequent treatment responsiveness in a more nonspecific way, across treatment modalities. Since such results were not reported in the previous studies investigating neuroimaging predictors of SRI response in OCD, it may be that methodological differences explain this discrepancy. Specifically, we propose that the use of SPM-based versus ROI-based methods of data analysis may have provided greater power in the current study to detect a focal area of significant correlation within the larger region nominally identified as PCC. Another possibility is that the current findings in PCC are attributable to the fact that this study was limited to subjects with contamination-related OCD. Therefore, it would be of great interest to reanalyze data sets from the earlier studies of this type, using SPM-based methods, to see 
whether loci of significant correlation could be found within PCC, despite having escaped detection using ROI-based methods of analysis.

Although contemporary neurocircuitry models of OCD have emphasized the role of OFC, anterior cingulate cortex, and the caudate nucleus, several functional imaging studies have also pointed to a role for PCC in OCD (Busatto et al. 2000; McGuire et al. 1994). In fact, PCC is known to communicate with anterior cingulate cortex via projections coursing through the cingulum bundle (Vogt and Pandya 1987), and is also purported to directly communicate with OFC (Cavada et al. 2000; Zald and Kim 1996), as well as the caudate nucleus (Kemp and Powell 1970). Hence, PCC is one area that is anatomically and functionally linked to the key elements of the OCD circuit (e.g., anterior cingulate cortex, OFC, and striatum). Therefore, though it remains unclear why functional neuroimaging measures within PCC would predict treatment response across therapeutic modalities, we speculate that it is somehow related to the role of PCC in modulating the fronto-striatothalamo-frontal circuitry implicated in OCD. Indeed PCC seems to be ideally positioned, based on its anatomical and functional connectivity, to modulate this critical circuit.

Of relevance, recent results from a morphometric MRI study of cingulotomy for OCD demonstrated volumetric reduction within PCC when comparing postoperative to pre-operative MRI data $(p<.05)$ (Rauch et al. 2000a). In a tandem study (Rauch et al. 2000a), using subcortical segmentation of the same MRI data set, the investigators also showed significant volumetric reductions within the body of caudate nucleus that were bilateral, specific, and significantly correlated with anterior cingulate lesion volume.

Though early conceptualizations of the limbic system (Papez 1937; also see MacLean 1990) as well as more recent publications (Maddock 1999) have raised the possibility that PCC plays a central role in emotion, the current prevailing wisdom maintains that this territory is principally involved in cognitive, perceptual, and evaluative functions (Olson et al. 1993; Sutherland and Hoesing 1993; Vogt et al. 1992, 2000). More specifically, one theory holds that PCC functions in concert with the hippocampal formation to primarily subserve mnemonic and spatial functions (Sutherland and Hoesing 1993). Of note, implicit sequence learning studies of OCD indicate that patients may utilize the hippocampal system to compensate for cortico-striatal dysfunction (Rauch et al. 1997, 2000b). Along these lines, the current findings prompt the hypothesis that patients who exhibit greater resting activity within PCC are more likely to derive benefit from SRIs, which have been hypothesized to have their therapeutic action on OFC, anterior cingulate cortex, striatum, and/or hippocampus (Baxter et al. 1992; Swedo et al. 1992; Rauch et al. 1998b;
Blier and Bouchard 1994; Mansari et al. 1995; Duman et al. 1997).

While the prospect of performing a neuroimaging test that can predict response to treatment is appealing, there are several important limitations to this study that should be appreciated. First, the number of subjects is small. Second, as we acknowledged, the selection of a narrow population of OCD subjects, suffering from contamination-related symptoms, limits our ability to generalize these findings to the broader OCD population. Third, negative findings in the current study could be due to type II errors. In this regard, one of the limitations of statistical parametric mapping is its reliance on spatial normalization. This may be especially problematic in cases where structural abnormalities and/or increased variability are present. For instance, abnormalities of caudate volume have been inconsistently reported in OCD (see Robinson et al. 1995; Rauch and Baxter 1998); resulting mis-registration involving the caudate in the current study could underlie our failure to find significant effects in this region.

In conclusion, the results of the current study, involving one cohort of patients with contaminationrelated OCD, indicate that pre-treatment PET measures of rCBF within OFC and PCC predicted subsequent improvement in OCD symptom severity following fluvoxamine treatment. These are robust findings that appear to be relatively independent of symptomatic state at the time of PET data acquisition. The use of neuroimaging methods to predict treatment response represents one strategy for potentially improving the management of OCD, as well as advancing our understanding regarding the pathophysiology of this disease.

\section{ACKNOWLEDGMENTS}

We acknowledge Lee Baer, Sandy Barrow, Adair Kendrick, Linda Leahy, Katherine McMullin, Peter Manzo, and Steve Weise for their assistance. This research was supported by NIMH grant RO1MH50275 (Dr. Jenike); additional support was provided by RO1MH60219 (Dr. Rauch) and the David Judah Research Fund. With regard to potential conflicts of interest, over the period during which this research was conducted, the investigators received funding from Solvay in the form of unrestricted educational grants, fellowship support, and occasional honoraria. Similarly, some of the investigators received fellowship support from Pfizer Inc., and occasional honoraria from a range of industry sponsors who produce serotonergic reuptake inhibitors, including Pfizer, Ciba, Lilly, Forest, and GlaxoSmithKline.

\section{REFERENCES}

Alpert NM, Berdichevsky D, Levin Z, Morris ED, Fischman AJ (1996): Improved methods for image registration. Neuroimage 3:10-18 
American Psychiatric Association (1987): Diagnostic and Statistical Manual of Mental Disorders, 3rd ed., Revised. Washington, DC, American Psychiatric Association.

Baer L (1994): Factor analysis of symptom subtypes of obsessive compulsive disorder and their relation to personality and tic disorders. J Clin Psychiatry 55(suppl 3):18-23

Baxter LR Jr, Schwartz JM, Bergman KS, Szuba MP, Guze $\mathrm{BH}$, Mazziotta JC, Alazraki A, Selin CE, Ferng HK, Munford P, Phelps ME (1992): Caudate glucose metabolic rate changes with both drug and behavior therapy for obsessive-compulsive disorder. Arch Gen Psychiatry 49:681-689

Beck AT, Ward CH, Mendelson M, Mock J, Erbaugh J (1961): An inventory for measuring depression. Arch Gen Psychiatry 4:561-571

Blier P, Bouchard C (1994): Modulation of 5HT release in the guinea pig brain following long-term administration of antidepressant drugs. Br J Pharmacol 113:485-495

Breiter HC, Rauch SL, Kwong KK, Baker JR, Weisskoff RM, Kennedy DN, Kendrick AD, Davis TL, Jiang A, Cohen MS, Stern CE, Belliveau JW, Baer L, O'Sullivan RL, Savage CR, Jenike MA, Rosen BR (1996): Functional magnetic resonance imaging of symptom provocation in obsessive compulsive disorder. Arch Gen Psychiatry 53:595-606

Brody AL, Saxena S, Schwartz JM, Stoessel PW, Maidment K, Phelps ME, Baxter LR Jr (1998): FDG-PET predictors of response to behavioral therapy versus pharmacotherapy in obsessive-compulsive disorder. Psychiatry Res: Neuroimaging 84:1-6

Busatto GF, Zamignani DR, Buchpiguel CA, Garrido GE, Glabus MF, Rocha ET, Maia AF, Rosario-Campos MC, Campi Castro C, Furuie SS, Gutierrez MA, McGuire PK, Miguel EC (2000): A voxel-based investigation of regional cerebral blood flow abnormalities in OCD using SPECT. Psychiatry Res: Neuroimaging 99:15-27

Cavada C, Company T, Tejedor J, Cruz-Rizzolo RJ, ReinosoSuarez F (2000): The anatomical connections of the macaque monkey orbitofrontal cortex. Cereb Cortex 10:220-242

Duman RS, Heninger GR, Nestler EJ (1997): A molecular and cellular theory of depression. Arch Gen Psychiatry 54:597-606

Friston KJ, Frith CD, Liddle PF, Frackowiak RSJ (1991): Comparing functional (PET) images: the assessment of significant change. J Cereb Blood Flow Metab 11:690-699

Friston KJ, Worsley KJ, Frackowiak RSJ, Mazziotta JC, Evans AC (1994): Assessing the significance of focal activations using their spatial extent. Hum Brain Mapping $1: 214-220$

Friston KJ, Holmes AP, Worsley KJ, Poline JP, Frith CD, Frackowiak RSJ (1995): Statistical parametric maps in functional imaging: a general approach. Hum Brain Mapping 2:189-210

Goodman WK, Price LH, Rasmussen SA, Mazure C, Fleischmann RL, Hill CL, Heninger GR, Charney DS (1989): The Yale-Brown Obsessive Compulsive Scale (Y-BOCS): Part I. Development, use, and reliability. Arch Gen Psychiatry 46:1006-1011

Kemp JM, Powell TPS (1970): The cortico-striate projections in the monkey. Brain 93:525-546
Leckman JF, Grice DE, Boardman J, Zhang H, Vitale A, Bondi C, Alsobrook J, Peterson BS, Cohen DJ, Rasmussen SA, Goodman WK, McDougle CJ, Pauls DL (1997): Symptoms of obsessive-compulsive disorder. Am J Psychiatry 154:911-917

MacLean PD (1990): The Triune Brain in Evolution: Role in Paleocerebral Function. New York, Plenum, pp 247-268

Maddock RJ (1999): The retrosplenial cortex and emotion; new insights from functional neuroimaging of the human brain. Trends Neurosci 22:310-316

Mansari ME, Bouchard C, Blier P (1995): Alteration of serotonin release in the guinea pig orbito-frontal cortex by selective serotonin reuptake inhibitors: Relevance to treatment of obsessive-compulsive disorder. Neuropsychopharmacology 13:117-127

Mataix-Cols D, Rauch SL, Manzo PA, Jenike MA, Baer L (1999): Factor-analyzed symptom dimensions predicting outcome with serotonin reuptake inhibitors and placebo in the treatment of obsessive-compulsive disorder. Am J Psychiatry 156:1409-1416

McGuire PK, Bench CJ, Frith CD, Marks IM, Frackowiak RS, Dolan RJ (1994): Functional anatomy of obsessive-compulsive phenomena. Br J Psychiatry 164:459-468

Oldfield RC (1971): The assessment and analysis of handedness: the Edinburgh Inventory. Neuropsychologia 9:97-113

Olson CR, Musil SY, Goldberg ME (1993): Posterior cingulate cortex and visuospatial cognition: Properties of single neurons in the behaving monkey. In Vogt BA, Gabriel $M$ (eds), Neurobiology of Cingulate Cortex and Limbic Thalamus: A Comprehensive Handbook. Boston, Birkhauser, pp 366-380

Papez JW (1937): A proposed mechanism of emotion. Arch Neurol Psychiat 38:725-743

Rauch SL (2000): Neuroimaging research and the neurobiology of obsessive compulsive disorder: Where do we go from here? Biol Psychiatry 47:168-170

Rauch SL, Baxter LR (1998): Neuroimaging of OCD and related disorders. In Jenike MA, Baer L, Minichiello WE (eds), Obsessive-Compulsive Disorders: Practical Management. Boston, Mosby, pp 289-317

Rauch SL, Jenike MA, Alpert NM, Baer L, Breiter HC, Savage CR, Fischman AJ (1994): Regional cerebral blood flow measured during symptom provocation in obsessivecompulsive disorder using ${ }^{15} \mathrm{O}$-labeled $\mathrm{CO}_{2}$ and positron emission tomography. Arch Gen Psychiatry 51:62-70

Rauch SL, Savage CR, Alpert NM, Dougherty D, Kendrick A, Curran T, Brown HD, Manzo P, Fischman AJ, Jenike MA (1997): Probing striatal function in obsessive compulsive disorder: A PET study of implicit sequence learning. J Neuropsychiatry 9:568-573

Rauch SL, Dougherty DD, Shin LM, Alpert NM, Manzo P, Leahy L, Fischman AJ, Jenike MA, Baer L (1998a): Neural correlates of factor-analyzed OCD symptom dimensions: a PET study. CNS Spectrums 3:37-43

Rauch SL, Whalen PJ, Dougherty DD, Jenike MA (1998b): Neurobiological models of obsessive compulsive disorders. In Jenike MA, Baer L, Minichiello WE (eds), Obsessive-Compulsive Disorders: Practical Management. Boston, Mosby, pp 222-253

Rauch SL, Kim H, Makris N, Cosgrove GR, Cassem EH, Savage CR, Price B, Nierenberg AA, Shera D, Baer L, Buch- 
binder B, Caviness V, Jenike MA, Kennedy DN. (2000a): Volume reduction in caudate nucleus following stereotactic lesions of anterior cingulate cortex in humans: a morphometric magnetic resonance imaging study. J Neurosurg 93:1019-1025

Rauch SL, Whalen PJ, Curran T, Shin LM, Coffey BJ, Savage CR, McInerney SC, Baer L, Jenike MA (2000b): Probing striato-thalamic function in OCD and TS using neuroimaging methods. In Cohen DJ, Goetz C, Jankovic J (eds), Tourette Syndrome and Associated Disorders. Philadelphia, Lippincott, Williams \& Wilkins. Advances in Neurology 85;207-224.

Rauch SL, Makris N, Cosgrove GR, Kim H, Cassem EH, Price BH, Baer L, Savage CR, Caviness VS, Jenike MA, Kennedy DN (2001a): A magnetic resonance imaging study of regional cortical volumes following stereotactic anterior cingulotomy. CNS Spectrums 6:214-222

Rauch SL, Dougherty DD, Cosgrove GR, Cassem EH, Alpert NM, Price BH, Nierenberg AA, Mayberg HS, Baer L, Jenike MA, Fischman AJ (2001b): Cerebral metabolic correlates as potential predictors of response to anterior cingulotomy for obsessive compulsive disorder. Biol Psychiatry 50:659-667

Robinson D, Wu H, Munne RA, Ashtari M, Alvir JM, Lerner G, Koreen A, Cole K, Bogerts B (1995): Reduced caudate nucleus volume in obsessive-compulsive disorder. Arch Gen Psychiatry 52:393-398

Saxena S, Brody AL, Maidment KM, Dunkin JJ, Colgan M, Alborzian S, Phelps ME, Baxter LR Jr. (1999): Localized orbitofrontal and subcortical metabolic changes and predictors of response to paroxetine treatment in obsessivecompulsive disorder. Neuropsychopharmacol 21:683693
Saxena S, Brody AL, Schwartz JM, Baxter LR Jr (1998): Neuroimaging and frontal-subcortical circuitry in obsessivecompulsive disorder. Br J Psychiatry 173(suppl. 35):26-38

Spitzer RL, Williams JBW, Gibbon M, First MB (1998): Structured Clinical Interview for DSMIII-R- patient version (SCID-OP). New York, NY, Biometrics Research Department

Sutherland RJ, Hoesing JM (1993): Posterior cingulate cortex and spatial memory: a microlimnology analysis. In Vogt BA, Gabriel M, editors. Neurobiology of Cingulate Cortex and Limbic Thalamus: A Comprehensive Handbook. Birkhauser, Boston, pp 461-477

Swedo SE, Pietrini P, Leonard HL, Schapiro MB, Rettew DC, Goldberger EL, Rapoport SI, Rapoport JL, Grady CL (1992): Cerebral glucose metabolism in childhood-onset obsessive-compulsive disorder: Revisualization during pharmacotherapy. Arch Gen Psychiatry 49:690-694

Vogt BA, Finch DM, Olson CR (1992): Functional heterogeneity in cingulate cortex: the anterior executive and posterior evaluative regions. Cereb Cortex 2:435-443

Vogt BA, Bush G, Absher JR (2000): Human retrosplenial cortex: where is it and is it involved in emotion? Trends Neurosci 23:195-197

Vogt BA, Pandya DN (1987): Cingulate cortex of the rhesus monkey; II. Cortical afferents. J Comp Neurol 262:271-289

Worsley KJ, Evans AC, Marrett S, Neelin P (1992): A three dimensional statistical analysis for rCBF activation studies in human brain. J Cereb Blood Flow Metab 12:900-918

Zald DH, Kim SW (1996): Anatomy and function of the orbital frontal cortex, I: Anatomy, neurocircuitry, and obsessive-compulsive disorder. J Neuropsychiatry Clin Neurosci 8:125-138 